\title{
O corpo expandido e os efeitos de presença em performances intermediais
}

The expanded body and the effects of presence in intermediais performance

\section{Resumo}

$\mathrm{O}$ artigo analisa o conceito de corpo expandido e os efeitos de presença em performances intermediais. O objetivo é o de investigar de que forma tecnologias digitais radicalizam algumas práticas permitindo que o corpo expandido do artista extrapole espaços delimitados na cena.

\section{Palavras-chave}

Corpo expandido; efeito de presença; tecnologias digitais; performances intermediais.

\begin{abstract}
The article analyses the concept of expanded body and the effects of presence in intermediais performances. The goal is to investigate how digital technologies radicalize some practices allowing the expanded body of the artist to break spaces surrounded by the scene.
\end{abstract}

\section{Keywords}

Expanded body; effects of presence; digital technologies; intermediais performances.

\footnotetext{
${ }^{1}$ Professora Adjunta do Curso de Direção Teatral e do Programa de Pós-Graduação em Artes da Cena da UFRJ. Pesquisa financiada com bolsa CAPES (Estágio Sênior) na Paris 3- Sorbonne Nouvelle.
} 
O efeito de presença é o sentimento que tem um espectador de que o corpo ou os objetos oferecidos a seu olhar (ou a seus ouvidos) encontram-se lá, no mesmo espaço e no mesmo tempo em que se encontram os seus; logo ele sabe que eles estão ausentes.

Josette Féral

Analisar o corpo expandido é refletir sobre o corpo mediatizado, atravessado por imagens digitais ou criado a partir de dispositivos que tomam a imagem digital como ferramenta de criação. Novos dispositivos tecnológicos e suportes, relações intermediais, processos neurais de recepção são realidades que não podem mais ser ignoradas, influenciando diretamente os mais diversos processos de criação. Nos espetáculos e performances intermediais, o corpo do ator/performer se desdobra em corpo-virtual. Assistimos não apenas a imagens projetadas, mas em muitos casos, a uma verdadeira metamorfose do corpo transpassado pela imagem. Corpo que é suporte e, ao mesmo tempo, "suporta" a imagem, transformando-se em um híbrido de si mesmo. Há, ainda, situações em que o ator/performer se relaciona com a imagem projetada, o que denominei imagem-paisagem ${ }^{2}$, não apenas como um simples cenário virtual, mas interferindo diretamente nela e a modificando através de um processo interacional. O corpo igualmente expandido é paisagem, projetando espaços distintos, para além do espaço cênico. Nesse sentido, não se trata apenas de uma imagem ilustrativa, mas de uma imagem que modifica o campo de percepção do espectador e do performer; uma imagem em trânsito e mutável na cena, que se desdobra através do movimento, modificando a percepção de espaço e tempo e do próprio corpo do artista.

Interessa investigar, nessa análise, novas sensorialidades em relação ao corpo do ator/performer atravessado pela virtualidade e expandido pelas imagens. De que modo efeitos de presença surgem a partir da relação interativa com o espectador? De que é formado o corpo expandido e quais relações se estabelecem entre o corpo em “carne e osso" e o corpo digital? Quando o corpo físico está ausente, qual é o papel desempenhado pelo corpo digital e quais são os efeitos de

${ }^{2}$ Conceito desenvolvido por mim no artigo "Poéticas cênicas em espetáculos intermediais: imagem e presença". O Percevejo online. Vol. 5, n.2, julho-agosto de 2014, pp.95-105. 
presença decorrentes? Quais procedimentos de criação se tornam, portanto, eficazes na inter-relação corpo/ator-imagem/espectador? Que implicações éticas estão presentes nas "metamorfoses" do corpo?

Faço uma distinção conceitual entre corpo físico, corpo digital (imagem) e corpo expandido, tendo clareza de que seus limites não são identificáveis, sendo transpassados constantemente. Entre o corpo físico e o digital, situo o corpo expandido em um entre-lugar que não se caracteriza por uma ausência, mas por ser interseccional. Nem carne, nem imagem, é híbrido, desdobrado aos olhos do espectador. Perpetua-se como sensação, como atravessamento, como aquilo que, em trânsito, entre dois lugares, não é possível localizar, co-existindo na cena e no imaginário do espectador. Um corpo por vezes disforme, sem limites predefinidos e que constantemente dialoga com outras espacialidades e temporalidades.

Com o objetivo de refletir sobre os efeitos de presença, divido em três categorias o corpo expandido, relacionando-o a grupos distintos de experiências que, a meu ver, são dialógicas. Na primeira delas, analiso o que chamo de corpo fantasmágorico e seus efeitos de presença. Para isso, investigo o espetáculo Norman, da companhia canadense 4dart. Em um segundo momento, a partir da ideia de corpo cibernético, defendida por Santaella (2003), aprofundo-me nas experiências de Eduardo Kac e, por último, analiso as possibilidades de interatividade na experimentação do corpo sensório realizada pelo grupo de pesquisadores Be another Lab.

\section{O corpo fantasmagórico: híbrido de carne e imagem}

Norman, do grupo canadense 4DArt, de Montreal, utiliza um dispositivo ótico chamado Pepper's Ghost, que produz efeitos de presença ao eliminar a presença da tela de projeção, colaborando para a qualidade de projeção da imagem dos personagens virtuais que se assemelham a espectros. A ilusão de ótica é obtida por meio da utilização de uma tela a 45 graus que reflete a luz proveniente de uma fonte de projeção colocada fora da cena, que o espectador não consegue identificar. É a técnica do holograma, desenvolvida pelos diretores Lemieux e Pilon desde a criação da companhia 4D art, em 1983. Norman conta a história da paixão 
VIS

Revista do Programa de Pós-graduação em Arte da UnB

de Peter Trosztmer, dançarino e coreógrafo, obcecado pelo movimento evocado pelos filmes. Ele vai até o escritório nacional do filme do Canadá, onde o diretor Norman MacLaren (1914-1987) criou a maior parte de sua obra para "penetrar literalmente em seus filmes [...] para dançar, dialogar e refletir com eles ${ }^{3 "}$. O espetáculo apresenta um duplo viés de investigação das imagens escolhidas para projeção. De um lado, baseado na obra do cineasta, imagens experimentais e poéticas, provenientes do cinema experimental e da animação, são utilizadas com o objetivo de "[...] contornar a utilização de palavras e a análise racional que lhe é atrelada." (Bressan, 2013: 323). De outro lado, aparecem depoimentos reais de não atores sobre a obra de McLaren, o que confere, segundo os diretores, um caráter documental ao espetáculo. O efeito obtido por meio da apresentação virtual de pessoas reais é o de uma aparência "diáfana", “[...] confundindo as pistas entre ficção, documentário, mas também entre a presença real de pessoas que não encenam um papel - que são elas mesmas [...] e sua presença transposta no espaço virtual" (Perrot, 2013: 336).

Uma reflexão premente é questionar o efeito da projeção virtual em cena dissociada da interação com o ator. É certo que os personagens virtuais podem ser pensados em sua autonomia e analisados independentemente de uma relação direta com o corpo físico do ator/performer. Ou seja, podemos obter efeitos de presença provenientes da ausência da materialidade do corpo em carne e osso, que dependerão do uso do espaço cênico, no qual incluo o espectador. Espaço que é, portanto, de projeção e projetivo, i.e., estamos falando de modos de projeção e de recepção do personagem virtual. Nessa análise, interessa refletir sobre o efeito de presença proveniente da interação entre corpo material e corpo virtual.

3 Apresentação de Norman no site da Internet de 4D Art. Disponível em: HTTP://www.4dart.com/spectacles,html. Acesso em: 31/05/2017. 


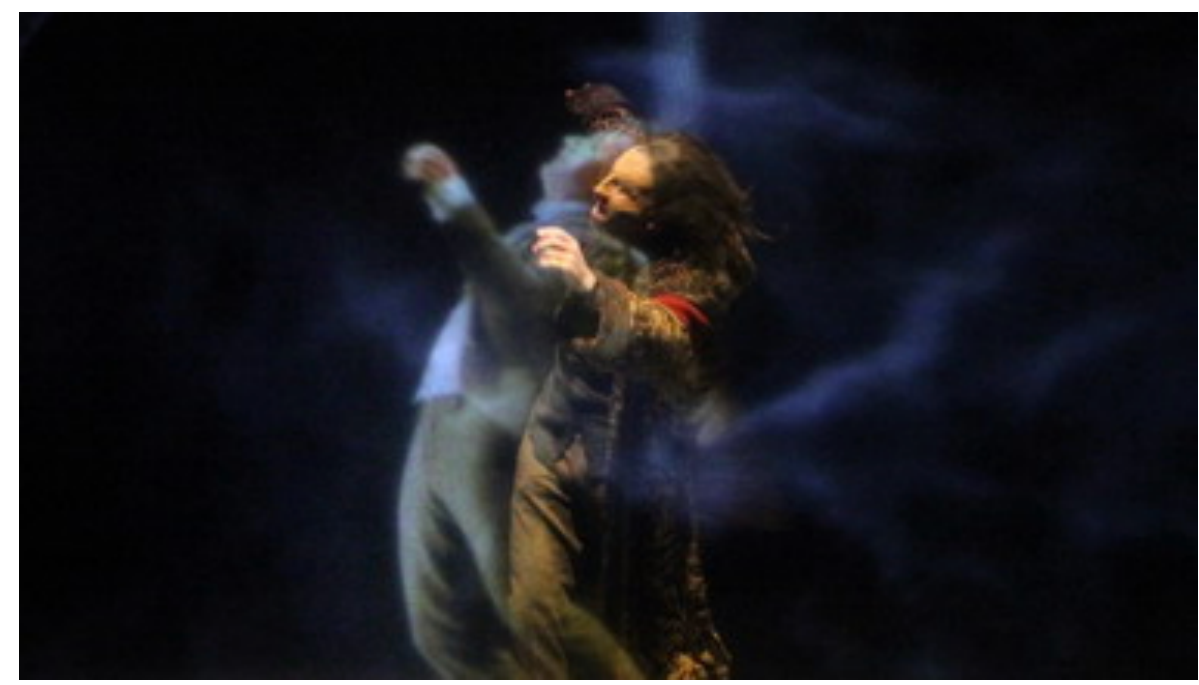

Cena de Norman, de Lemieux e Pilon, na qual o corpo do ator se funde ao corpo digital.

Há uma troca poética de um imaginário construído em cena por meio da interação entre o corpo físico do ator, ao representar o personagem Peter, e a projeção dos personagens virtuais. O corpo (em carne e osso) do ator funde-se ao corpo virtual do personagem, expandindo-se na relação com a imagem. Para Lemieux, um dos diretores, o espectador percebe a ampliação do efeito de presença por meio de uma fantasmagorização dos personagens que são percebidos como projeções do mundo imaginário de Peter; ao mesmo tempo em que apresentam uma dupla conotação, uma vez que se trata de uma estratégia ficcional que visa tão somente a ampliação do efeito de presença. Os limites entre o corpo em carne e osso e o corpo virtual, em algumas cenas, não podem ser definidos, o que gera a impressão de um corpo híbrido, expandido e desdobrado no espaço cênico.

\section{O corpo cibernético}

Em As artes do corpo cibernético, Lúcia Santaella analisa a reconfiguração do corpo humano, na passagem do século XX ao XXI. Do contato inextrincável com a tecnologia, surge um corpo híbrido mediado pelas máquinas, o que a autora denomina como "corpo biocibernético" (2003: 67). A artes interativas trazem à tona um novo estatuto do corpo, transfigurado por tecnologias em expansão que modificam o modo de percepção, de processamentos de informações, de memória, transformando nossas capacidades cognitivas. Santaella chama a atenção para a invisibilidade presente em diversas manifestações artísticas e para uma 
forma enigmática do corpo. Classificando as artes do corpo biocibernético em 8 tipos $^{4}$, mapeia parte significativa da produção contemporânea, destacando obras importantes, tais como: Omnipresence (1993), de Odete Orlan, em que o corpo da artista sofre inúmeras intervenções cirúrgicas que são encenadas através de eventos performáticos, em um verdadeiro teatro cirúrgico; Stelarc e seu corpo protético presente em diversos trabalhos, entre eles Exoskeleton (1997), no qual o artista construiu uma máquina com seis pernas pneumáticas para caminhar; entre outros exemplos.

Em 1990, aos 43 anos, Orlan inicia uma série de intervenções cirúrgicas (foram nove no total), transformando-as em performances. O desejo da artista foi o de "inventar um autorretrato", a partir de um programa de computador, com o objetivo de criar um corpo híbrido, reflexo de "deusas da mitologia grega", tais como "Diana", mas também como "Mona Lisa" (Orlan, 1995: 8). Nas salas de cirurgias, havia sempre música, e a equipe cirúrgica vestia-se com roupas de costureiros famosos. Todas as intervenções foram gravadas em vídeo, inclusive as incisões cirúrgicas, como nos programas médicos atualmente transmitidos pela TV a cabo. Féral faz uma análise do trabalho de Orlan destacando que a performer buscou, através das cirurgias, com as metamorfoses do corpo, uma espécie de "recusa em aderir a uma identidade definida de uma vez por todas" (Féral, 2015: 211). Há um risco real de morte a cada investida, o que leva o espectador a se perguntar sobre os limites ético-artísticos que envolvem tais experiências. Haveria, por conseguinte, um extremo a ser alcançado? Quais são os limites do corpo?

O corpo de que fala Orlan é um corpo novo, um corpo do futuro que aparece como resultado de um discurso, como virtualidade de um relato, como representação de um desejo. É um corpo ficção, um corpo real certamente como memória, um portador de marcas: inicialmente as da própria Orlan como sujeito desejoso, em seguida as da cultura na qual ela se inspira. (Féral, 2015: 217)

O corpo ficção a que se refere Féral, ligado diretamente à virtualidade, é um corpo que não existe, apesar de toda mutação, é enigma, desprovido de si, e

\footnotetext{
${ }^{4}$ Artes dos corpos: remodelado (1), protético (2), esquadrinhado (3), plugado (4), telepresença (5), simulado (6), digitalizado (7) e molecular (8).
} 
que caminha a um outro - "Eu sou um outro: eu sou o ponto mais extremo da confrontação. Como o artista Stelarc, eu acredito que o corpo é obsoleto. Ele não pode mais lidar com a situação. Nós sofremos mutação.” (Orlan, 1995: 9). O modo como Orlan decide romper com as normas sociais reguladoras, que impõem um modelo de beleza feminino, traz uma discussão ética relevante: como ser e aparecer na sociedade? O que o corpo do artista deve refletir? Como assumir os riscos de uma presença, de "uma ética do corpo?, como questiona Dieguez, ao citar Pavlosky (Dieguez, 2014: 5). Não é possível narrar a si mesmo sem, contudo, se relacionar com o outro e com a sociedade, ainda que criticamente através de uma profunda e radical modificação do corpo.

Stelarc, assim como Orlan, acredita que é na metamorfose do corpo que se dá o encontro do sujeito com o outro de si mesmo. Através de próteses, o performer cria uma interface com a tecnologia, que interage em tempo real através de uma dupla via de movimentos. Em Third Hand (1992), por exemplo, um braço robótico é instalado sobre o braço do performer. Não há como controlar os movimentos que são gerados através de correntes elétricas, o que cria uma espécie de “teatro do Cyborg” (Pluta, 2011: 116): um corpo híbrido, meio homem, meio máquina. "Stelarc evoca que a tecnologia faz parte do corpo humano e encarna, de certa forma, a figura do ciborgue que forma uma entidade indissociável do robótico e do orgânico." (Pluta, 2011: 116). Em Fractal Flesh (1995) ou Carne Fractal, colaboradores remotos conectavam-se ao corpo do artista "[...] via sistema de teleconferência PictureTel e conexões de ISDN de três cidades europeias." (Kac, 2013: 93). Eles manipulavam seus membros à distância, estimulando respostas musculares involuntárias, através do uso de eletrodos. O efeito de presença reside, em ambas as experiências, em um campo híbrido: naquilo que não sendo nem biológico, nem tecnológico, não tendo uma especificidade, amplia os sentidos de uma presença espectral, não passível de ser controlada, nem pelo homem, nem pela máquina.

\section{Efeitos de presença na telepresença}

Tecnologias virtuais, ligadas à telepresença ou à presença virtual, radicalizam algumas práticas permitindo que o corpo expandido do artista extrapole espa- 
ços delimitados na cena. Lúcia Santaella (2007) faz uma retrospectiva do surgimento do conceito de telepresença e de seus usos, situando seu aparecimento com os estudos de Minsky (1980), posteriormente com Laurel (1990). Segundo ela, a telepresença é "o meio que nos permite estar com nosso corpo em outro espaço, que pode ser um ambiente gerado por computador, um ambiente transmitido por câmera de vídeo, ou uma combinação dos dois" (Snataella, 2007: 277). Eduardo Kac, poeta e artista plástico, que integrou a histórica exposição Como vai você, geração 80?, no Parque Lage, no Rio de Janeiro, desenvolve um trabalho, reconhecido no Brasil e no exterior, investigando as relações entre telepresença e bioarte. Para Kac, a telepresença é um conceito que surge da interseção entre computadores, robótica e telecomunicações.

Em 1986, o artista cria sua primeira performance utilizando a telerrobótica, na Galeria de Arte do Centro Empresarial Rio, no Rio de Janeiro. Os visitantes da exposição ao chegar deparavam-se com um "[...] robô antropomórfico sem fio de 2,15 metros de altura (RC Robot) no papel de anfitrião, que conversava bidirecionalmente com os visitantes da exposição." (Kac, 2013: 138). O robô era manipulado e sua voz (humana) transmitida em tempo real via ondas de rádio. Kac apresentou uma performance dialógica, unindo o robô e o ator Otávio Donasci, que criou um ser chamado "videocriatura": usava botas pretas e uma roupa preta cobrindo todo o corpo, inclusive a cabeça, substituída por uma tela de vídeo. Ambos, robô e videocriatura, interagiam e conversavam: a voz de um interlocutor, não visível, era transmitida como se fosse a voz do próprio robô que respondia à videocriatura que, ao final, terminava por suicidar-se. Para Kac (2013: 150), a arte da telepresença pode ser definida como aquela que cria "[...] um contexto único no qual os participantes são convidados a vivenciar mundos remotos inventados em perspectivas e escalas outras que não a humana".

Em 1997, o artista amplia sua pesquisa, introduzindo o conceito de biotecnologia; a Biologia, nas últimas décadas, passa a ser vista como uma ciência da informação, modificada pelas relações com a tecnologia. Com a engenharia genética, o homem tenta cada vez mais o controle dos processos de reprodução e mutação dos organismos vivos. Tais experiências, para além de um debate ético, es- 
VIS

Revista do Programa de Pós-graduação em Arte da UnB

timulou Kac a criar obras visando a questionar os limites do corpo em sua interface com as máquinas. Realizada aos 11 de novembro de 1997, na Casa das Rosas, em São Paulo, Cápsula do Tempo é uma performance na qual Kac implantou em tempo real um microchip em seu corpo e transmitiu a experiência ao vivo na Internet e na TV.

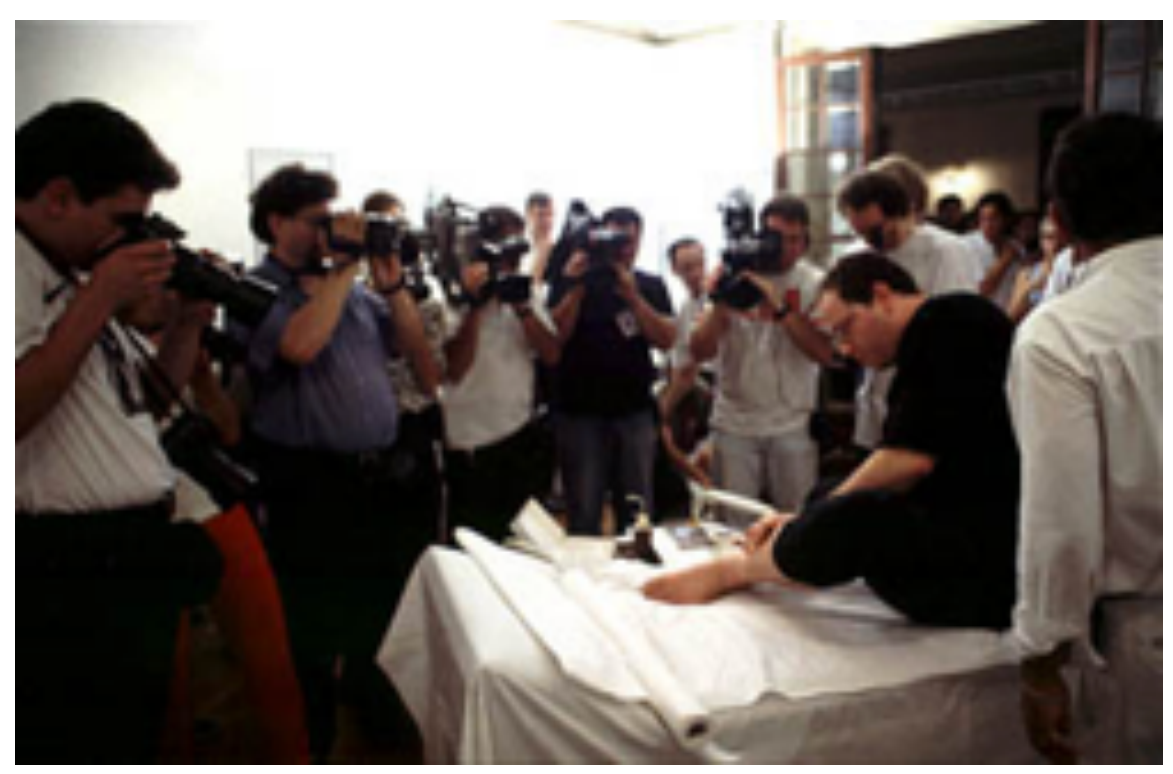

Eduardo Kac em Cápsula do tempo

“A obra é um sistema distribuído que liga um evento-instalação local, uma intervenção site specific [...] na qual o próprio site é tanto meu corpo quanto um banco de dados remoto e um simulcast ao vivo na televisão e na web" (Kac, 2014: 241). O artista questiona politicamente o uso que se faz das máquinas na cultura digital, uma vez que nossos corpos estão impregnados de dispositivos eletrônicos e maquínicos e não temos controle sobre eles. Onde começa o corpo, onde termina a máquina é uma das questões éticas mais prementes na bioarte, e é dela que Kac tenta tratar em Cápsula do tempo.

O objeto que dá titulo à obra é um microchip que contém um número de identificação programado e é integrado com uma bobina e um capacitador, tudo hermeticamente lacrado em vidro biocompatível. A escala temporal da obra compreende o efêmero e o permanente, ou seja, entre os poucos minutos necessários para a conclusão desse procedimento básico, a implantação do microchip, e o caráter permanente do implante. Como sucede com outras cápsulas do tempo underground, é debaixo da pele 
que essa cápsula do tempo se projeta para o futuro. (Kac, 2013: 241)

A experiência foi a primeira de um implante de microchip digital em seres humanos e inaugura uma discussão sobre a memória do corpo, não apenas ligada às experiências vividas mas, a partir desse momento, sujeita também à copresença de memórias artificiais, transmitidas on-line, transpassando os limites do corpo. Um corpo híbrido e expandido que gera um efeito de presença para além de sua própria superfície. O efeito de presença, nesse caso, se articula à ideia da morte do corpo físico, de quão perenes nós somos e de como a tecnologia, quando parte inerente do corpo, é capaz de salvaguardá-lo ao produzir imagens que se projetam para o futuro. Imagens que são armazenadas em um banco de dados, um dia igualmente perenes. De que forma podemos reter a memória do corpo? É uma questão que traduz o paradoxo da morte e da ineficácia da tentativa de reter, através da imagem, a memória e as impressões do corpo vivo do artista. Na experiência de Kac, ao transmitir informações sobre seu corpo, que passam a ser armazenadas em um banco de dados, o artista ganha um número de série, podendo ser identificado para além da visão do corpo físico. A pele não mais delimita o corpo, “[...] ela se torna o local de transmutações contínuas" (Kac, 2014: 247), e o que se passa dentro do corpo torna-se visível através da transmissão digital em rede, o que leva ao assombramento e ao fascínio de romper com os limites do corpo. O corpo expandido não se limita aos seus contornos próprios (a pele); não é passível de ser controlado porque, no caso da telepresença, é mediatizado e suas imagens são integradas à rede; permite que se amplie o efeito de presença ao revelar imagens da ordem de uma invisibilidade; um corpo sem pele, cuja memória é também digital e armazenada fora de si.

[...] ficamos fascinados devido às novas possibilidades de um corpo expandido contemplando a noção de vida estendida; e ficamos assustados porque essas tecnologias, desenvolvidas originalmente para ajudar as pessoas doentes ou fisicamente debilitadas, não são, na verdade, desejáveis para um corpo sadio e, portanto, renovam nosso medo de confrontar nossa própria mortalidade. (Kac, 2014: 246) 
VIS

Revista do Programa de Pós-graduação em Arte da UnB

The Machine to Be Another: meu corpo é outro, é do outro, eu sou um outro

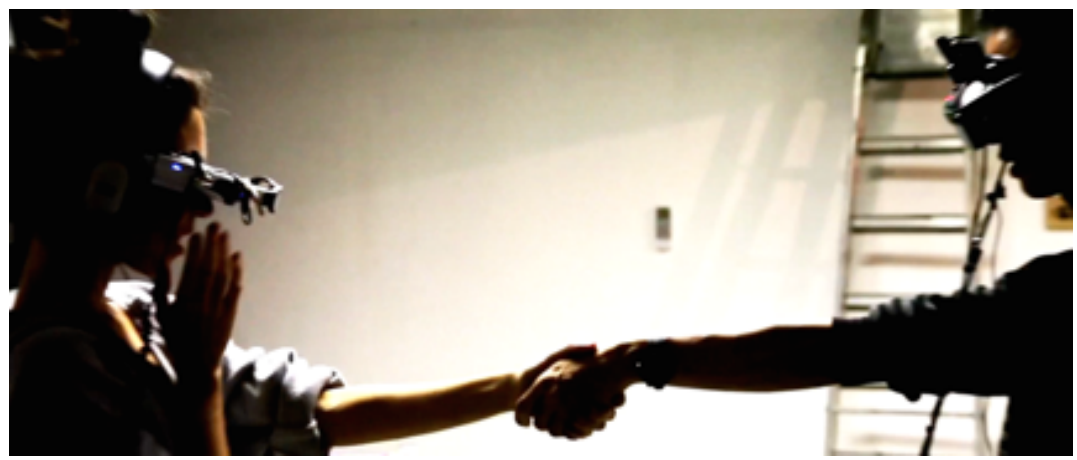

Foto retirada do site The machine to be Another"/documentation

The Machine to Be Another (2013/2017) é uma performance realizada a partir de uma experiência imersiva que investiga a relação entre empatia e identidade, através da possibilidade do participante "habitar" o corpo e adotar o ponto de vista de uma outra pessoa. Realizada pelo coletivo internacional e interdisciplinar BeAnotherLab ${ }^{6}$, a performance, que se utiliza da telepresença e de conhecimentos provenientes da neurociência, teve a colaboração de artistas residentes em Estruch (Março a Junho de 2013, em Sabadell, Espanha), no Madrid - MIT M + Vision Hacking Medicine Event (Julho de 2013) e, recentemente, vem sendo apresentada em festivais do mundo inteiro. O projeto partiu do interesse em investigar o modo como emoções, ações e sensações podem contribuir para ativar a empatia, a percepção do próprio corpo e do corpo do outro, além de ativar a área cognitiva ligada à formação de conceitos.

Na neurociência, há uma série de protocolos com o intuito de auxiliar indivíduos que sofrem neuropatologias ligadas à locomoção, expressão ou percepção do mundo. O grupo decidiu estudar alguns desses experimentos e adequá-los à pesquisa artística. Interessante notar que há vários diretores e artistas que se interessam pelo tema. Peter Brook, por exemplo, nos anos 90, em seu "ciclo do cérebro", dedica-se à pesquisa neurocientífica em sua relação com o teatro, a partir do estudo da obra do neurocientista Oliver Sacks, morto recentemente. Em Como

${ }^{5}$ The machine to be another é registrado através de uma Creative Commons não comercial chamada Share Alike, como open source art, o que significa que qualquer interessado pode utilizá-lo.

${ }^{6}$ Daniel Gonzalez-Franco, Arthur Pointeau, Christian Cherene e Philippe Bertrand, entre outros. 
confundir sua mulher com um chapéu, Sacks relata neuropatologias de seus clientes que vêem suas vidas transformadas a partir de uma radical cisão com o modo de olhar o mundo e de interagir com ele. Brook, completamente fascinado por essas histórias, realiza dois espetáculos sobre o tema, L’homme qui (1997) e, no ano seguinte, Je suis un phénomène (1998), baseado na obra do neurologista Alexander Luria. Em uma célebre cena de L'homme qui, o personagem de Yoshi Oida está diante de um grande telão fazendo a barba, mas só retira os pêlos de um dos lados do rosto. A outra metade do corpo não é reconhecida por ele, devido à neuropatologia. O médico induz que ele olhe então para a tela e, com surpresa, o paciente se dá conta da não-percepção do próprio corpo.

Na experiência proposta, o coletivo BeAnotherLab cria um ambiente simples, composto por duas poltronas uma de frente para a outra, separadas por uma cortina, um espelho, uma mesa, alguns objetos e um capacete de realidade virtual com óculos Rift $^{7}$ e fones de ouvido. Cada participante se senta na poltrona de frente para o outro. Ao colocar o capacete, com os óculos e fones de ouvido, o espectador/usuário percebe que o que vê não advém de seu campo de visão, e sim do campo do performer. A experiência permite que o usuário não só "interaja com os objetos, mas também com a narrativa interna dos pensamentos e memórias do performer [...] de um modo profundamente imersivo" (BERTRAND et al.). Há uma câmera utilizada pelo performer que transmite seu ponto de vista em tempo real, enquanto ele narra para o usuário, através de um microfone, uma narrativa curta autobiográfica, nem sempre linear porque ligada aos objetos presentes na sala - "[...] a foto de alguém, um brinquedo de criança, um pacote de cigarros, o espelho, etc." - (BERTRAND et al.), o que torna a experiência interativa. Quando o usuário manipula algum objeto, ele ouve a voz do performer trazendo à tona a memória da vivência. Ao promover a imersão no corpo do outro, através da percepção de seus movimentos e da reprodução de sua visão, a performance visa a provocar a empatia entre seus participantes.

\footnotetext{
${ }^{7}$ Head-mounted display, ou HMD, é um dispositivo de vídeo usado na cabeça como um capacete e com fones de ouvido, como uma interface através da qual o usuário pode experimentar um ambiente de realidade virtual.
} 
O efeito [...] provém da decalagem entre a visão e os gestos. $\mathrm{O}$ que os impulsiona? São seus ou provém do outro? Alguns minutos são necessários para se familiarizar com esta desencarnação progressiva. Logo que a cortina é retirada, e nos vemos em face ao outro, a experiência encontra sua ressonância mais profunda, um tipo de empatia com você mesmo, mais curiosa que lúdica a ser experimentada. (Catala, 2015: n.p)

O efeito de presença expande a percepção do corpo do participante da experiência que, ao invés de sentir seus movimentos, passa a interagir como se fosse o performer, ampliando seu campo sensorial e perceptivo. Ao habitar o corpo do outro, os criadores da performance pretenderam criar o que eles denominam "bugs perceptivos ${ }^{8}$ ", espaços originais e novos de experimentação da realidade através do contato com a virtualidade. A experiência vai ao encontro do desejo de ser um outro, presente na maior parte dos atores que buscam, através de técnicas diversas, “sentir-se na pele dos personagens". No método das ações físicas de Constantin Stanislavski, por exemplo, a ferramenta "se mágico" nada mais é do que, a partir da relação com o contexto, o estímulo para a realização das ações da personagem - como o sujeito agiria se fosse um outro? é a pergunta motriz. O estudo stanislavskiano balizou uma série de pesquisas posteriores nas artes cênicas: Grotowski, Barba, Mnouchkine, Brook são alguns dos sucessores stanislavskianos. Cada um deles, à sua maneira, desenvolveu pesquisas tendo como base o método russo. A relação entre corpo e memória ancestral (o corpo réptil) em Grotowski; as relações neurais na inter-relação imagem e percepção em Brook, "a sequência de estados puros" e "o estado de presença" (Féral, 2010: 64) em Mnouschkine e a cinestesia na dramaturgia orgânica de Barba têm como ponto de partida o método psicofísico stanislavskiano.

Em 1991, neurocientistas da Universitá de Parma, na Itália, a partir de um estudo realizado com macacos, descobriram os chamados neurônios-espelho. $\mathrm{Na}$ experiência, verificaram que tais neurônios se ativavam quando um movimento era executado (como levar um alimento à boca) mas, também, quando apenas se visualizava o mesmo movimento. A área do cérebro era, então, ativada sem a ne-

\footnotetext{
8 'Il y a plusieurs bugs perceptifs que nous proposons au cours de l'expérience, dont l'un est de pouvoir se serrer la main à soi-même depuis la perspective de quelqu'un d'autre" (Arthur Pointeau - artigo na revue française)
} 
cessidade de uma compreensão conceitual da ação. Havia uma espécie de impulso interno da ação que poderia ou não ser concretizada. Isso significa que, quando estamos diante de alguém que executa uma ação, internamente reagimos a ela e a reproduzimos, ainda que não a realizemos. Esta descoberta é interessante não apenas porque se relaciona diretamente a metodologias de trabalho do ator, mas também ao processo de recepção do espectador.

Nos seres humanos, como nos macacos, a visão dos atos reali-
zados pelos outros produz uma ativação imediata das áreas mo-
toras incumbidas da organização e execução desses atos e, atra-
vés dessa ativação, é possível decifrar o significado dos 'even-
tos motores' observados, isto é, entendê-los em termos de mo-
vimentos centrados em objetivos. Tal entendimento é comple-
tamente isento de qualquer mediação reflexiva, conceitual e/ou
linguística, uma vez que é baseado exclusivamente no vocabu-
lário de atos e no conhecimento motor do qual depende nossa
capacidade de agir. Ademais, também como ocorre com o ma-
caco, tal entendimento não é limitado a atos motores singulares,
mas é extensível a toda uma cadeia de atos (Rizzolatti; Siniga-
glia, 2008: 125).

A partir da pesquisa, verificou-se que, quando não havia um objetivo claro, quando a mímica das ações era vazia de intenção (por exemplo, havia uma ação mecânica de levar uma colher vazia à boca), o neurônio-espelho não era ativado e, por conseguinte, não havia impulso à ação, nem tampouco empatia. Gabriele Sofia (2014) faz uma associação interessante desse experimento com a pesquisa de Stanislavski apresentada em A preparação do ator, mais especificamente no terceiro capítulo Ação, no qual ele descreve a cena em que a estudante do Teatro de Arte de Moscou, Maria, tenta encontrar um broche perdido no palco, de forma nada convincente. Quando ele lhe diz que havia mesmo um broche perdido e, caso não o encontrasse, ela estaria fora do Teatro, Maria se põe a procurar com muita "verdade". Stanislavski conclui que toda ação física deve ter, portanto, um objetivo claro. A "verdade cênica" relaciona-se diretamente a essa ideia. Podemos igualmente relacioná-la ao efeito de presença. O que faz um ator/performer impactar com sua presença o espectador? Como desdobrar essa presença variável, abstrata, muitas vezes não definível, em espetáculos e performances intermediais? É evidente que o uso de tecnologias complexifica a discussão que é, por si só, bastante ampla e nada simples. 
Especificamente, a descoberta neurocientífica traz uma contribuição importante para a relação entre ator/performer e espectador porque aponta para o debate sobre a interatividade das ações, sua percepção e seus modos de recepção, levando à elaboração de um pensamento sobre a "experiência performativa do espectador" (Sofia, 2014: 1). The machine to be another gerou três outras performances: La noia de les lagrimes vermelles, Empathy towards an immigrant e In Dancing on the feet, nas quais a relação com o usuário/espectador é, do ponto de vista ético, problematizada. Todas as três utilizam-se da estrutura tecnológica da The Machine to be another, sendo desdobramentos dela. Na primeira, uma préadolescente de doze anos chamada Sarah narra, através de uma ilustração, sua história para a mãe Anna. A mãe é uma artista que sugere a performance para a filha com o objetivo de se aproximar dela e de modificar a relação entre ambas.

A performance foi também apresentada a uma plateia, permitindo que o espetáculo "The Machine" funcionasse como uma ferramenta para a expressão artística de Sarah. De acordo com a mãe de Sarah, a experiência ajudou Sarah a assumir uma atitude mais segura e feliz em sua vida cotidiana, que acreditamos ter sido impulsionado pelo reconhecimento de sua mãe e da plateia sobre seu talento e criatividade. $\mathrm{O}$ experimento foi sugerido por sua mãe e artista - Anna - que queria se aproximar de sua filha. (Bertrand et. al., 2014: n.p) ${ }^{9}$

Empathy towards an immigrant é uma performance realizada por um imigrante senegalês morador da Espanha. Youssoupha. "empresta" seu corpo e suas impressões para espectadores através do uso do Machine, conta histórias do Senegal, da sua infância e da relação com a música e a dança. O objetivo da performance é estimular um outro olhar do espectador para os imigrantes africanos na Europa, modificando a relação e o preconceito existente. In Dancing on the feet traz a experiência de uma cadeirante, Victoria, e toda sua dificuldade de locomoção e as mudanças corporais pelas quais passou. Victoria performa através do encontro com a dançarina Cristina que não sofre de nenhuma disabilities e oferece seu corpo como uma possibilidade de libertação das limitações de Cristina. A ex-

\footnotetext{
${ }^{9}$ The performance was also presented to an audience, allowing "The Machine" to work as a tool for artistic expression for Sarah. According to Sarah's mother, the experience helped Sarah to assume a more secure and happy attitude during her everyday life, what we believe is driven by the recognition of her creative talent by her mother and the audience. The experiment was suggested by her artist mother - Anna - that wanted to get closer to her daughter.
} 
periência carrega a possibilidade virtual de uma liberação de forças presentes no corpo, de um impulso de ação ativo, mas que não pode ser reproduzido porque limitado neurologicamente. Ao final, a troca de lugar promove um outro entendimento sensível do corpo proveniente da ausência daquilo que não se pode mudar - seja pela falta, seja pela presença.

Os usuários tendem a demonstrar compaixão em relação aos artistas - alegando que a experiência aumentou sua conscientização sobre a condição social dos performers. Além disso, na maioria dos casos, observamos que os usuários queriam abraçar o performer no final do experimento, sorrindo para eles. Embora puramente qualitativas, as declarações dos usuários revelaram que eles se "aprofundaram na vida dessa outra pessoa", o que contribuiu para a sua experiência de que na história "poderia ser eu em seu lugar". (Bertrand et al., 2014: n.p)

\section{A eficácia do efeito de presença}

Pensar o efeito de presença a partir do uso de dispositivos tecnológicos de imersão nos leva a outra dimensão da cena, à partilha de uma experiência sensorial, antes inimaginada. No caso do Lab, através da vivência de uma experiência expandida, ser o outro implica deixar de perceber a si mesmo e fisicamente habitar, ainda que provisoriamente, o corpo do outro. Há um efeito, evidentemente, de ilusão advindo do uso da tecnologia que propõe uma cisão radical entre a percepção neurológica do corpo e a realidade. O interessante é que tal efeito promove a identificação e a empatia, elementos também bastante investigados nas artes de modo geral. O processo de identificação do espectador deve-se à estimulação por uma troca de lugar, a ser o outro, a ocupar literalmente o lugar do performer. A eficácia da experiência talvez possa ser compreendida de modo mais aprofundado à medida que o uso de tecnologias tornem-se mais comuns nas artes, o que, acredito, ocorrerá, com frequência cada vez maior, devido ao barateamento de equipamentos e ao desenvolvimento de novos softwares e equipamentos ainda mais sofisticados, com relação aos recursos, e acessíveis.

A relação entre arte, ciência e tecnologia é instigante e, no início do século XXI, se amplia com a vasta utilização de dispositivos tecnológicos e de informações que circulam em rede. Refletir sobre como a ciência pode contribuir para a arte e, em especial, para as artes da cena é uma questão relevante na contempora- 
neidade, uma vez que envolve o debate sobre as relações entre corpo/memória, criação/recepção. É evidente que o contato com a tecnologia modificou radicalmente a experiência de concepção de uma obra artística, bem como de sua espectatorialidade. A memória subjetiva do ator e do espectador é atravessada pela memória coletiva das imagens, por um modo de apreensão e de percepção da realidade que é construído através de inúmeras referências digitais que modificam noções fundamentais, como a de corpo, espaço e tempo.

\section{Referências}

BERTRAND, Philippe; GONZALEZ-FRANCO, Daniel; CHERENE, Christian; POINTEAU, Arthur. The machine to be another: embodiment performance to promote empathy among individuals. Disponível em: http://doc.gold.ac.uk/aisb50/AISB50-S16/AISB50-S16-Bertrand-paper.pdf. Acesso em: $25 / 09 / 2015$.

BRESSAN, Yannick. L'inscription physique et cognitive du personnage: effet de présence. In: BOURASSA, Renée; POISSANT, Louise (Org.). Personnage virtuel et corps perfomatif. Québec: Presses de l'Université du Québec, 2013, pp.305-313.

CATALA, Laurent. La machine à être un autre. Disponível em: http://www.makery.info/2015/04/17/la-machine-a-etre-un-autre/. Artigo publicado em Acesso em 25 de setembro de 2015.

FÉRAL, Josette. Encontros com Ariane Mnouchkine: Erguendo um monumento ao efêmero. Trad. Marcelo Gomes. São Paulo: SESC/SENAC, 2010.

. Além dos limites: Teoria e prática do teatro. Trad. Jacob Guinsburg et al. São Paulo: Perspectiva, 2015.

FÉRAL, Josette (Org). Pratiques Performatives: BodyRemix. Press de l’Université du Québec/Presses Universitaires de Rennes, 2012.

GURGEL, Gabriela L. Poéticas cênicas em espetáculos intermediais: imagem e presença. In: O Percevejo online. Vol. 5, n.2, julho-agosto de 2014, pp.95-105.

KAC, Eduardo. Telepresença e bioarte: Humanos, Coelhos e Robôs em Rede. São Paulo: Editora da USP, 2013.

ORLAN. I do not want to look like... Orlan on becoming Orlan. Women's Art Magazine, n. 64, maio-junho, 1995.

PERROT, Edwiges. Le performeur virtuel: Parcours dans l'oeuvre de 4D Art par Michel Lemieux. In: BOURASSA, Renée; POISSANT, Louise (Org.). Person- 
VIS

Revista do Programa de Pós-graduação em Arte da UnB

nage virtuel et corps performatif. Québec: Presses de l'Université du Québec, 2013, pp. 327-337.

RIZZOLATTI, G.; SINIGAGLIA, C. Mirrors in the brain: how our minds share actions and emotions. Oxford: Oxford University Press, 2008.

SANTAELLA, Lucia. Linguagens líquidas na era da mobilidade. São Paulo: Paulus Editora, 2007.

As artes do corpo cibernético. In DOMINGUES, Diana (Org.). Arte e Vida no século XXI. São Paulo: Editora UNESP, 2003, pp. 65-94.

SOFIA, Gabriele. Neurones mirois et intention dilatée. Vers un étude de l'expérience performative du spectateur. Du récepteur ou l'art de déballer son pique-nique. Actes de colloques et journées d'étude. Université de Rouen, 2012. Disponível em: http://ceredi.labos.univ-rouen.fr/public/?neurones-miroirs-etintention.html. Acesso em: 25 de setembro de 2015. 